\title{
As disputas, o desenho e a aplicação dos recursos do FGTS entre 1998 e 2017
}

\author{
Disputes, design and application of resources from the Guarantee \\ Fund for Length of Service between 1998 and 2017
}

Piero Boeira Locatelli [l]

\section{Resumo}

Este trabalho analisa as disputas, o desenho e a aplicação dos recursos do FGTS (Fundo de Garantia do Tempo de Serviço) destinados ao financiamento habitacional entre 1998 e 2017. A análise evidencia que o fundo cumpriu uma função central no atendimento habitacional para a população de baixa renda nesse período, especialmente a partir da concessão de subsídios com esse fim, chamados de descontos. A sua criação em 1998 foi seguida por uma expansão dos recursos com essa finalidade. Nos anos 2000, houve uma ampliação desses recursos especialmente com a resolução n. 460 do CCFGTS e o programa Minha Casa Minha Vida. $O$ fundo continuou a subsidiar a habitação social também em meio a um contexto de políticas guiadas pela austeridade no âmbito federal a partir de 2012.

Palavras-chave: financiamento habitacional; FGTS; política habitacional; subsídios.

\begin{abstract}
The main goal of this study is to analyze the disputes, the design and the application of resources from the Guarantee Fund for Length of Service (FGTS) destined to housing loans between 1998 and 2017. The analysis shows that the fund played a key role in providing housing for the lowincome population in this period, especially by granting subsidies for this purpose. The creation of housing subsidies in 1998 was followed by an expansion of this type of resources. The 2000s have seen an increase in these subsidies, especially with resolution no. 460 of CCFGTS and with the implementation of the Minha Casa Minha Vida housing program. The fund has continued to subsidize social housing even in the context of austerity-driven policies in the federal sphere from 2012 onwards.
\end{abstract}

Keywords: housing loan; FGTS; housing policy; subsidies. 


\section{Introdução}

O fundo público, em geral, e o crédito regulado, em particular, desempenham papel estruturante em todo o processo de acumulação capitalista brasileiro (Oliveira, 1988; Cintra, 2009). Isso inclui o financiamento da habitação desde a década de 1930, quando o governo buscou a criação e o uso de fundos com esse fim (Bonduki, 1998).

A habitação tornou-se uma pauta central do governo brasileiro na década de 1960, quando o governo militar criou o Banco Nacional da Habitação e um sistema para financiá-la, o Sistema Financeiro de Habitação (Azevedo e Andrade, 1982, p. 62). Ainda que o banco tenha sido extinto, em 1986, esse sistema segue vigente há mais de cinquenta anos após a criação do fundo e ainda é a principal fonte do crédito habitacional no País.

Este trabalho trata de um dos pilares desse sistema, o Fundo de Garantia do Tempo de Serviço (FGTS). 0 objetivo é analisar as disputas, o desenho e a aplicação dos recursos do FGTS no período entre 1998 e 2017, tendo como foco os recursos destinados ao financiamento habitacional e, especialmente, o subsídio concedido com os recursos do fundo. Por meio desses subsídios, o fundo poderia "promover acesso à moradia adequada aos segmentos populacionais de menor renda" (CCFGTS, 2018), ainda que isso nem sempre tenha ocorrido.

A realização deste trabalho partiu da revisão bibliográfica sobre o tema, a qual se somou a análise da legislação e das demais normas que regem o FGTS, além da consolidação de dados orçamentários do fundo e do Orçamento Geral da União (OGU). Em um segundo momento, foram realizadas entrevistas semiestruturadas com dez agentes públicos e do setor privado que tiveram papel relevante na elaboração ou na execução das políticas descritas ao longo do trabalho. Entre os entrevistados, estão funcionários e ex-presidentes da Caixa Econômica Federal, dois ex-ministros da Cidade e um presidente da Câmara Brasileira da Indústria da Construção. Essas entrevistas cooperaram para uma compreensão melhor das fontes primárias e para o entendimento dos processos descritos ao longo deste trabalho.

\section{FGTS, fundo público}

Desde os anos 1950, o welfare state (estado de bem-estar social) determinou o padrão do financiamento da economia capitalista. Ainda que a formação capitalista sempre tenha sido ligada a recursos públicos, a partir de então ela passou a ser feita com regras perenes e pactuadas dentro da sociedade, em uma esfera pública ou em um mercado institucionalmente regulado (Oliveira, 1988, p. 9). No entanto, o padrão de welfare dos países centrais jamais foi implantado de forma plena nas economias periféricas, nas quais as reformas de caráter social-democrata possuem diversas particularidades e distinto grau de sucesso (Pochmann, 2004, p. 3).

No Brasil, o provimento de habitação fez parte desse projeto de welfare state particular e incompleto. Em 1964, o recém-empossado governo militar criou o Banco Nacional da Habitação, para gerir e financiar uma política destinada a "promover a construção e aquisição da casa própria, especialmente pelas classes de menor renda" (Brasil, 1964). 
Esse banco teve escassez de recursos orçamentários em seus dois primeiros anos (Azevedo e Andrade, 1982, p. 62). Para sanar esse problema, o governo estabeleceu o Sistema Financeiro de Habitação, com duas fontes de recursos: o Sistema Brasileiro de Poupança e Empréstimo, voltado às camadas de renda mais alta, e o FGTS, voltado às mais baixas.

O FGTS foi formado a partir da contribuição de $8 \%$ da folha de pagamento dos trabaIhadores formais. Com essa contribuição, os trabalhadores tornavam-se cotistas do fundo, e suas contas eram remuneradas por juros entre $3 \%$ e $6 \%$ ao ano. Os saques das contas eram restritos e só podiam acontecer em casos específicos, como a demissão sem justa causa.

A remuneração fixa e as restrições para os saques permitiram a concessão de empréstimos abaixo dos cobrados pelo restante do mercado. Assim, com a criação FGTS, o governo buscou uma solução para a habitação distinta daquela adotada nos países centrais, que foi calcada especialmente no orçamento público (Trindade, 1971, p. 237).

Cinquenta anos após a sua criação, 0 FGTS ainda mantém as suas principais características. Dentro do arranjo estabelecido pelo Sistema Financeiro de Habitação (SFH), o FGTS continua a ser a maior fonte de financiamento para a habitação de interesse social no País e, em determinados momentos, torna-se a principal fonte do mercado imobiliário como um todo. Em 2018, o FGTS concedeu R\$57,3 biIhões em empréstimos para a habitação (Brasil, 2019) enquanto o Sistema Brasileiro de Poupança e Empréstimo (SBPE) concedeu R\$54,9 bilhões naquele mesmo ano (CBIC, 2019).

Assim como o orçamento público, que financia grande parte das políticas voltadas à educação e saúde, o FGTS cumpre o papel de fornecer uma mercadoria (no caso, a moradia) ao trabalhador. Esse fornecimento desonera o salário direto pago pelas empresas ao trabaIhador e cria, assim, um salário indireto semeIhante àquele descrito por Oliveira (1988) ao comentar sobre o papel do fundo público no welfare state:

O crescimento do salário indireto, nas
proporções assinaladas, transformou-se
em liberação do salário direto ou da ren-
da domiciliar disponível para alimentar o
consumo de massa. O crescimento dos
mercados, especialmente do de bens de
consumo duráveis, teve, portanto, como
uma de suas alavancas importantes, o
comportamento já assinalado das despe-
sas sociais públicas ou do salário indire-
to. (p. 10)

Isto posto, cabe apresentar o debate que insere o FGTS e seus descontos na constituição de um sistema de provimento habitacional feito pelo Estado brasileiro.

\section{FGTS e os subsídios habitacionais no Brasil}

A política habitacional tornou-se uma pauta central do governo brasileiro somente na década de 1960. Em busca de legitimação, a ditadura militar viabilizou um sistema voltado à habitação ainda no seu primeiro ano no poder, com a criação do Banco Nacional da Habitação (Azevedo e Andrade, 1982, p. 39). Para viabilizar as operações do BNH, o Governo Federal criou um sistema de provimento de habitação que prescindia do orçamento público, e que seria calcado em contradições entre seu objetivo social e sua modelagem financeira. 
De um lado, o sistema tinha o objetivo de trazer habitação para as classes de menor renda e, dessa forma, ajudar na construção de conjuntos habitacionais para a população vinda de "favelas, mocambos e outras aglomerações em condições sub-humanas de habitação" (Brasil, 1964). De outro lado, o SFH previa a sua viabilidade financeira no longo prazo. 0 sistema prescindia de recursos orçamentários "a fundo perdido" e buscava a sua sustentação especialmente através do uso de mecanismos de juros e correção monetária.

As principais fontes financeiras do sistema, o FGTS e o SBPE, tinham em seu horizonte a sustentabilidade financeira. Como apontam Eloy, Costa e Rossetto (2013):

Havia, ainda, um sistema de subsídios internos e cruzados: taxas de juros crescentes diretamente proporcionais aos valores de financiamento e inferiores aos custos de captação para financiamentos mais baixos, de menor valor de prestação, a fim de viabilizar o acesso aos mutuários de menor renda. Mecanismo que, em tese, promoveria uma compensação interna e não comprometeria o equilíbrio financeiro do sistema. (p. 3)
Apesar do sistema de subsídios, as contradições iniciais entre o seu sistema de financiamento e o seu objetivo social levaram o Banco Nacional da Habitação (BNH) a distanciar-se dos objetivos iniciais e a tornar-se um sistema baseado na premissa da sustentabilidade financeira, fracassando em cumprir a sua função social (Silva, 1989).

Durante os anos da ditadura militar, os recursos que financiavam o $\mathrm{BNH}$, incluindo os do FGTS, "passaram paulatinamente a privilegiar os grupos de maior rendimento, causando graves distorções aos objetivos sociais do banco" (Azevedo e Andrade, 1982, p. 102). Como apontam Azevedo e Andrade (ibid., p. 100), "embora em meados de 1979, o FGTS representasse $42 \%$ das disponibilidades do BNH, aos setores populares couberam, como se viu, minguados recursos".

A elevada taxa de inflação fez com que o SFH tivesse grandes problemas financeiros, agravados no início dos anos 1980 . Nesse período, foram elaboradas propostas visando a sua reformulação, inclusive dentro do governo. Mas o processo de reformulação do BNH foi abortado, e o banco foi extinto no final de 1986 (Brasil, 1986). O governo de José Sarney

Tabela 1 - Financiamentos habitacionais concedidos através de SFH até 31 de dezembro de 1980

\begin{tabular}{l|c|c}
\hline \multicolumn{1}{c|}{ Clientela } & Unidades financiadas & $\%$ \\
\hline Mercado popular* & 1.004 .884 & 35,0 \\
Mercado econômico** & 627.824 & 21,8 \\
Mercado médio*** & 1.241 .175 & 43,2 \\
\hline Total & 2.873 .883 & 100,0 \\
\hline
\end{tabular}

* Cohabs e habitações construídas diretamente pelo BNH para população de baixa renda.

** Cooperativas Habitacionais, Institutos, Mercados de Hipotecas.

*** Recon e SBPE.

Fonte: Azevedo e Andrade (1982, p. 100). 
passou a administração dos recursos do SFH para a Caixa Econômica Federal, no caso do FGTS, e para o Conselho Monetário Nacional, no caso do SBPE. Apesar da mudança administrativa, as duas fontes financeiras do SFH foram mantidas com as suas antigas regras.

Essa desarticulação do sistema facilitou que houvesse um desvio na finalidade dos gastos do SFH, que se distanciaram ainda mais da produção de habitação social, e todas as tentativas de reforma ampla do sistema e da política habitacional na Nova República fracassaram (Arretche, 1996). Ao contrário de outros setores, que foram reformados de maneira ampla com a constituinte de 1988, a política habitacional não foi modificada.

Nesse período, o FGTS teve um uso político-partidário que ajudou a sustentar os frágeis acordos partidários da Nova República. Com o acirramento desse uso durante o governo Collor, o sistema chegou perto da falência em 1993, e as contratações com o fundo foram suspensas entre 1992 e 1994 (Cardoso e Aragão, 2013, p. 19).

Na segunda metade da década de 1990, a estabilidade inflacionária e um ambiente econômico menos volátil permitiram uma retomada gradual da concessão de créditos habitacionais no âmbito do SFH.

No ano seguinte à sua posse, o governo de Fernando Henrique Cardoso criou dois programas habitacionais calcados no crédito do FGTS: o Pró-Moradia e a Carta de Crédito. O Pró-Moradia operava com empréstimos concedidos ao poder público, fosse ele um município, uma unidade da federação ou uma empresa estatal. 0 programa combinava os recursos do fundo com contrapartidas do governo local e previa a necessidade de os estados e municípios estarem adimplentes com outras obrigações relacionadas ao fundo, o que terá consequências sobre a sua execução (Lorenzetti, 2001).

Já a Carta de Crédito era um programa de financiamento direto a pessoas físicas, em contraste aos outros programas direcionados diretamente às empresas. Criado em 1995, o programa tinha três modalidades: aquisição de unidade habitacional nova ou usada, construção de unidade habitacional e a conclusão, ampliação ou melhoria de unidade habitacional (Brasil, CCFGTS, 1995). O programa também contou com uma modalidade associativa, focada em pessoas físicas organizadas em condomínios, associações e sindicatos que visassem à construção de pequenos condomínios. Voltado inicialmente à baixa renda, já naquele momento ele não cumpriu essa função (Lorenzetti, 2001, p. 23).

Entre os dois programas, a Carta de Crédito recebeu a maior parte dos recursos, 75,8\% do total entre 1997 e 1998 (Arretche, 2002, p. 440).

Paralelamente a esse processo de mudança nas linhas de crédito do Sistema Financeiro Habitacional, a gestão de Fernando Henrique Cardoso também buscou implantar o Sistema Financeiro Imobiliário (SFI), um sistema que buscava a integração entre o mercado de crédito imobiliário e o mercado de capitais. Através da securitização de títulos imobiliários, que seriam negociados livremente no mercado, o sistema buscava prescindir do SFH, regulado pelo mercado.

Com taxas de juros superiores ao SFH, o SFI não teve como atender à população-alvo das políticas de subsídio vigente. Assim sendo, "até 2003, o desempenho do SFI foi 
Tabela 2 - Atendimento com recursos do FGTS entre 1997 e 2003 por programa e faixa de renda - \%

\begin{tabular}{l|r|r|r|r}
\hline \multicolumn{1}{c|}{ Programa } & Até 3 SM & 3 a 5 SM & 5 a 10 SM & 10 SM ou mais \\
\hline PAR & - & - & 100,00 & - \\
Pró-Moradia & 100,00 & - & - & - \\
Apoio à produção & - & - & - & 100,00 \\
Carta de Crédito Associativa & 1,90 & 13,90 & 34,50 & 49,70 \\
Carta de Crédito Individual & 6,20 & 15,10 & 50,10 & 28,60 \\
\hline Total & 8,50 & 12,60 & 50,40 & 28,50 \\
\hline
\end{tabular}

Fonte: Bonduki (2008, p. 80).

pífio, muito aquém do esperado, não obstante o surgimento de agentes especializados e de estímulos diversos" (Eloy, Costa e Rossetto, 2013, p. 8).

Em suma, como se pode ver na Tabela 2, os créditos do FGTS, nesse período, acabaram concentrados em faixas de renda elevadas, e não naquelas abaixo de 3 salários mínimos, em que se concentra o déficit habitacional. Do total do crédito concedido pelo fundo, somente $8,5 \%$ atendeu às famílias dessa faixa de renda.

\section{Os descontos do FGTS}

Este trecho do trabalho trata da trajetória dos subsídios diretos concedidos no âmbito do FGTS para a aquisição de moradias que, nos documentos do fundo, recebem o nome de descontos. Por ser concedido sem expectativa de retorno, esse subsídio teria o potencial de ampliar as faixas de renda atendidas pelos financiamentos do fundo, servindo àqueles que não conseguiriam acessá-lo pelos empréstimos concedidos dentro do SFH (CCFGTS, 2018).
Desde a sua constituição, no final da década de 1990, os descontos constituem "reserva específica, com contabilização própria" (Brasil, 1998b). Isso nos permite ver como se deu a execução deles ao longo do tempo, conforme Quadro 1.

0 ano de 1998 é o ponto de partida desta análise por se tratar do início da concessão de subsídios diretos pelo fundo.

\section{A criação dos descontos}

O FGTS começou a conceder subsídios habitacionais de maneira explícita em 1998. Naquele momento, os subsídios passaram a ter uma contabilidade separada dos demais empréstimos do fundo. Chamados de "descontos", esses subsídios eram inversamente proporcionais à renda do beneficiário e concedidos "mediante redução no valor das prestações a serem pagas pelo mutuário ou pagamento de parte da aquisição ou construção de imóvel" (Brasil, 1998a). Em sua criação, o Governo Federal determinou que a sua concessão não poderia ocorrer em detrimento da rentabilidade 
Quadro 1 - Orçamento total do FGTS e dos descontos entre 1998 e 2017

\begin{tabular}{|c|c|c|c|}
\hline Ano & $\begin{array}{c}\text { Descontos } \\
\text { (valor orçado)-R\$ }\end{array}$ & \% do total & $\begin{array}{c}\text { Orçamento total } \\
\text { do FGTS - R } \$\end{array}$ \\
\hline 1998 & $493.498,71$ & 4,85 & $10.179 .000,00$ \\
1999 & $1.053 .605,63$ & 5,10 & $20.672 .000,00$ \\
2000 & $954.098,65$ & 7,27 & $13.115 .000,00$ \\
2001 & $1.002 .877,42$ & 9,33 & $10.754 .000,00$ \\
2002 & $1.199 .967,53$ & 10,94 & $10.965 .000,00$ \\
2003 & $1.034 .882,19$ & 9,57 & $10.810 .000,00$ \\
2004 & $1.286 .711,76$ & 8,07 & $15.943 .000,00$ \\
2005 & $2.422 .814,40$ & 11,37 & $21.300 .000,00$ \\
2006 & $3.586 .529,16$ & 18,30 & $19.600 .000,00$ \\
2007 & $3.385 .939,32$ & 15,46 & $21.902 .000,00$ \\
2008 & $2.740 .597,78$ & 6,85 & $40.003 .575,30$ \\
2009 & $6.786 .233,60$ & 14,75 & $46.005 .600,00$ \\
2010 & $8.107 .404,46$ & 10,75 & $75.413 .205,00$ \\
2011 & $8.283 .201,30$ & 11,14 & $74.352 .400,00$ \\
2012 & $9.796 .782,69$ & 13,65 & $71.786 .000,00$ \\
2013 & $12.007 .495,52$ & 14,30 & $83.970 .000,00$ \\
2014 & $11.268 .777,72$ & 13,44 & $83.832 .700,00$ \\
2015 & $10.200 .187,65$ & 12,22 & $83.444 .000,00$ \\
2016 & $9.534 .003,07$ & 9,91 & $96.184 .800,00$ \\
2017 & $10.628 .599,92$ & 12,58 & $84.475 .000,00$ \\
2018 & $9.500 .000,00$ & 13,10 & $72.500 .000,00$ \\
\hline
\end{tabular}

Fonte: elaboração própria a partir de relatórios financeiros do FGTS. Valor corrigido com base no IPCA, considerando como base dezembro de cada ano e atualizando os valores para dezembro de 2018.

do fundo, explicitando a contradição entre a autossustentação financeira e o atendimento às camadas de renda mais baixa da população.

Antes da criação dos descontos, as taxas variavam conforme a renda de cada família. Ou seja, quanto maior fosse a renda familiar, maior seria a taxa de juros do empréstimo. A menor taxa era de $3 \%$ ao ano, destinada às famílias que recebiam até um salário mínimo. Já a maior era de $7 \%$, destinada às parcelas de renda mais alta atendida pelo fundo.
Com a criação dos descontos, as taxas foram unificadas em $6 \%$ ao ano, e o subsídio era responsável por compensar a diferença entre a taxa anterior e a nova. Esse tipo de desconto, voltado ao equilíbrio financeiro das operações de empréstimo, recebeu o nome de "desconto equilíbrio". Dessa forma, os subsídios não reduziram as taxas de juros da maior parte dos mutuários. Os únicos que tiveram a sua parcela efetivamente reduzida foram aqueles na faixa de renda mais alta atendida pelo fundo. 
O governo justificou esta, assim como outras medidas voltadas ao mercado imobiliário, como uma ferramenta de combate ao desemprego (Brasil, 1998a). Mas o objetivo da concessão desses subsídios extrapolava essa questão. A concessão dos descontos também fazia parte do projeto de implementação do Sistema de Financiamento Imobiliário. Naquele período, o governo tentava implantar o sistema, que buscava a criação de um mercado secundário de créditos imobiliários. 0 sistema permitiria a compra de créditos pelas securitizadoras e, dessa forma, havia a expectativa de que os créditos habitacionais, incluindo aqueles do FGTS, pudessem ser negociados em um mercado secundário.

Para a securitização de ativos imobiliários, seriam necessárias a padronização e a homogeneização de diversos produtos que, a princípio, têm características distintas - justamente o que acontecia com os empréstimos do FGTS anteriores à criação dos descontos. Os subsídios cumpriam o papel de normalizar as taxas de juro do fundo para que os seus créditos pudessem lastrear os títulos negociados no âmbito do Sistema Financeiro Imobiliário. $O$ então presidente Fernando Henrique Cardoso expôs essa intenção nos motivos que acompanham a Medida Provisória enviada ao Congresso, em que afirma que "a taxa de juros única corrobora para a padronização dos contratos, possibilitando, assim, o desenvolvimento de mercados secundários de ativos imobiliários e o estímulo à atração de mais recursos do mercado financeiro para o setor" (ibid.).

Os contratos do FGTS nunca foram negociados em um mercado secundário, mas os subsídios concedidos com essa intenção permaneceram em vigência. Naquele momento, os descontos foram utilizados principalmente em programas criados no final da década de 1990, como o Pró-Moradia, a Carta de Crédito Individual e a Carta de Crédito Associativo (Magnabosco e Freitas, 2015). Nos anos posteriores à criação do subsídio, os descontos do FGTS começaram a ser usados para outros fins além daqueles previstos inicialmente.

Quadro 2 - Mudanças nos descontos concedidos pelo FGTS com a resolução n. 289

\begin{tabular}{|l|c|c|c|}
\hline \multicolumn{1}{|c|}{ Renda familiar-R\$̦ } & \multicolumn{1}{|c|}{$\begin{array}{c}\text { Taxa anterior } \\
\text { à resolução }\end{array}$} & $\begin{array}{c}\text { Taxa posterior } \\
\text { à resolução }\end{array}$ & $\begin{array}{c}\text { Diferencial coberto } \\
\text { pelos descontos }\end{array}$ \\
\hline até 390,00 & $3,0 \%$ a.a. & $6 \%$ a.a. & $3,00 \%$ a.a. \\
de 390,01 a 650,00 & $3,5 \%$ a.a. & $6 \%$ a.a. & $2,50 \%$ a.a. \\
de 650,01 a 910,00 & $4,3 \%$ a.a. & $6 \%$ a.a. & $1,70 \%$ a.a. \\
de 910,01 a 1.170,00 & $5,1 \%$ a.a. & $6 \%$ a.a. & $0,90 \%$ a.a. \\
de 1.170,01 a 1.430,00 & $5,9 \%$ a.a. & $6 \%$ a.a. & $0,10 \%$ a.a. \\
de 1.430,01 a 1.560,00 & $7,0 \%$ a.a. & $6 \%$ a.a. & - \\
\hline
\end{tabular}

Fonte: elaboração própria a partir da resolução n. 289 do CCFGTS (CCFGTS, 1998). 
A partir de 1999, os descontos passaram a cobrir mais encargos e custos relacionados aos empréstimos, e, em 2000, o fundo começou a subsidiar parte do diferencial de juros do agente financeiro. Então estabelecido em $2 \%$, o diferencial de juros é a remuneração do agente financeiro que concede os empréstimos com base no funding do FGTS. Os descontos também começaram a cobrir a taxa de administração do agente financeiro do fundo, a um custo de $\mathrm{R} \$ 25$ mensais nos empréstimos concedidos a pessoas físicas com renda familiar bruta de até $\mathrm{R} \$ 2.000$ (Brasil, 1998b).
Os descontos foram prorrogados em 2001 (Brasil, CCFGTS, 2001), no momento em que o governo realizou uma nova política de subsídios para a habitação com base no OGU e em contrapartidas de governos estaduais e municipais, o Programa de Subsídio à Habitação Social (ibid.). Esse modelo de concessão de subsídios foi expandido pelo CCFGTS em dois momentos nos primeiros anos do governo de Luiz Inácio Lula da Silva (Brasil, CCFGTS, 2003a e 2003b), e permaneceu vigente até 2004, quando, com a resolução n. 460 do CCFGTS, aconteceu uma relevante mudança na concessão de subsídios.

Quadro 3 - Principais marcos regulatórios do FGTS entre 1998 e 2003

\begin{tabular}{|l|l|l|}
\hline \multicolumn{1}{|c|}{ Medida } & \multicolumn{1}{|c|}{ Data } & \multicolumn{1}{c|}{ Mudança } \\
\hline Medida provisória n. 1.671 & $24 / 6 / 1998$ & $\begin{array}{l}\text { Permite ao CCFGTS conceder descontos e exige contabilidade } \\
\text { própria para isso. }\end{array}$ \\
\hline Resolução n. 289 & $30 / 6 / 1998$ & $\begin{array}{l}\text { Unifica as taxas de juros do fundo em 6\% ao ano. Os descontos } \\
\text { cobrem a diferença para as antigas taxas. }\end{array}$ \\
\hline Resolução n. 340 & $26 / 4 / 2000$ & $\begin{array}{l}\text { Descontos passam a cobrir diferencial de juros do agente financeiro } \\
\text { (2\% ao ano). }\end{array}$ \\
\hline Resolução n. 392 & $6 / 6 / 2002$ & $\begin{array}{l}\text { Descontos passam a cobrir a taxa de administração do agente } \\
\text { financeiro (R\$25,00 mensais). }\end{array}$ \\
\hline Resolução n. 394 & $30 / 10 / 2003$ & Veda a duplicidade de descontos entre o PSH e o FGTS. \\
\hline
\end{tabular}

Fonte: elaboração própria a partir da legislação citada. 
O papel do FGTS na criação do Fundo de Arrendamento Residencial

O papel do FGTS no atendimento das parcelas de baixa renda da população não se resumia à concessão de subsídios. 0 fundo também cumpriu um papel central na constituição da principal política de atendimento à população de baixa renda desse período, o PAR (Programa de Arrendamento Residencial).

0 programa buscava atender à população com renda familiar de até seis salários mínimos através do arrendamento residencial, com opção de compra ao final do contrato de 180 meses (Brasil, 1999). Ele tinha como fonte de recursos um fundo criado exclusivamente para esse fim, o Fundo de Arrendamento Residencial (FAR).

Naquele momento, o FGTS foi a principal fonte de recursos do FAR. 0 primeiro empréstimo do FGTS para o FAR foi autorizado em junho de 1999 , quando foram concedidos $R \$ 2,4$ bilhões (em valores nominais) com um prazo de retorno de 20 anos (Brasil, 2000). Nos dez anos seguintes, o FGTS faria empréstimos ao FAR anualmente, como é possivel ver no Quadro 4. Esse processo só foi interrompido com a criação do Minha Casa Minha Vida, quando recursos do OGU foram alocados no FAR em grande volume.

\section{Resolução n. 460}

Os descontos do FGTS passaram por uma mudança substancial em 2004, quando o fundo começou a aportar recursos com o objetivo explícito de reduzir o valor das prestações dos setores de menor renda da população. A resolução n. 460 do Conselho Curador do FGTS estabeleceu que deveriam ser alocados recursos "para descontos sob a forma de redução do valor da prestação e pagamento de parte da aquisição ou construção de imóvel, para famílias com renda bruta mensal de até dois salários mínimos" (Brasil, 2004).

Quadro 4 - Empréstimos concedidos pelo FGTS ao FAR entre 1999 e 2009

\begin{tabular}{|c|c|}
\hline Ano & \multicolumn{1}{|c|}{ Valor (em R\$) } \\
\hline 1999 & $425.512 .050,22$ \\
2000 & $1.852 .016 .466,68$ \\
2001 & $1.184 .143 .614,72$ \\
2002 & $1.920 .309 .316,02$ \\
2003 & $2.579 .365 .808,82$ \\
2004 & $1.862 .970 .062,83$ \\
\hline
\end{tabular}

\begin{tabular}{|c|r|}
\hline Ano & \multicolumn{1}{|c|}{ Valor (em R\$) } \\
\hline 2005 & $2.194 .788 .684,68$ \\
2006 & $2.483 .912 .323,11$ \\
2007 & $1.125 .680 .033,66$ \\
2008 & $587.948 .301,80$ \\
2009 & $48.978 .891,52$ \\
\hline
\end{tabular}

Fonte: elaboração própria a partir de relatórios financeiros do FGTS. Valor corrigido com base no IPCA, considerando como base dezembro de cada ano e atualizando os valores para dezembro de 2018. 
Essa medida teve um forte impacto na ampliação dos financiamentos para famílias "até então pouco beneficiadas pelos empréstimos lastreados em recursos do Fundo" (Cardoso e Aragão, 2013, p. 30). Esses subsídios ganharam o nome de "desconto complemento", pois visavam complementar a capacidade de pagamento dos beneficiários.

A busca de viabilidade financeira do fundo continuava presente e, para que isso fosse possível, os descontos não tinham origem nas contas vinculadas dos cotistas do fundo, mas nos seus resultados financeiros. "Dessa forma, esses recursos não têm obrigatoriedade de retorno e podem ser utilizados 'a fundo perdido', ampliando sobremaneira a capacidade de atendimento do FGTS às faixas de menor renda" (Royer, 2009, p. 88).

Com a resolução n. 460, os descontos previstos nas resoluções estabelecidas pelo governo anteriormente continuaram em vigor. O fundo continuava a cobrir, por exemplo, a remuneração dos agentes financeiros nos mesmos moldes já previstos em 1998. O valor continuou a ser pago tendo como base de cálculo o saldo devedor inicial.

A concessão de subsídios cresceu em grande proporção a partir de então, com um aumento de $173,54 \%$ em 2005 e de $67,20 \%$ em 2006. Com ela, ocorreu um crescimento de todo o mercado imobiliário no País, e, a partir de 2005, as contratações com recursos do SBPE e do FGTS atingiram seu ápice, que ficou conhecido como o boom imobiliário do governo Lula (Maricato e Royer, 2017, p. 152).

Esse forte crescimento do mercado imobiliário não teria decorrido apenas de mudanças na concessão de funding, mas também de uma mudança mais ampla na legislação que regia o setor. Segundo o então secretário nacional de habitação, Jorge Hereda, foi necessário primeiramente reformar os regulatórios do setor para só posteriormente "começar a discutir subsídio e política pública" (Hereda, 2019).

Essas mudanças teriam ocorrido principalmente a partir da aprovação da lei n. 10.391, que mudava os parâmetros da alienação fiduciária, além de estabelecer o patrimônio de afetação e a instituição do pagamento de incontroverso. Essa legislação também ajudaria a romper uma resistência da Caixa Econômica Federal em conceder empréstimos, especialmente para empresas, devido aos diversos problemas pelos quais o banco e o FGTS haviam passado no início dos anos 1990. Assim, essa "melhora" no ambiente regulatório e as mudanças nos mecanismos de avaliação da Caixa foram essenciais para que o FGTS fizesse essa concessão de subsídios (ibid.).

A resolução n. 460 tampouco foi a única mudança relevante no funding do período. 0 Governo Federal tomou medidas para aumentar a disponibilidade do SBPE, para as rendas mais altas, e também tentou implantar outro sistema de subsídios para as parcelas de menor renda da população, contando, dessa vez, com o orçamento público. Havia um reconhecimento de que parte da população não conseguia adquirir uma moradia pelo SFH e, dessa forma, necessitava de outros auxílios para fazê-lo (Eloy, 2013). Com esse objetivo, ainda em 2005, foi criado o SNHIS (Sistema Nacional de Interesse Social) e o Fundo Nacional de Habitação de Interesse Social (FNHIS) (Brasil, 2005).

O desenho da concessão de subsídios previsto na resolução n. 460 e no SNHIS foi parcialmente ao encontro do que era previsto no projeto Moradia, uma série de propostas 
elaboradas pelo PT entre 1999 e 2000 no Instituto Cidadania e que foi a base do programa de governo do futuro presidente Luiz Inácio Lula da Silva na área. Essa proposta previa a participação do Orçamento Geral da União com recursos não onerosos atrelados aos recursos do FGTS. 0 projeto também defendia a reativação do crédito imobiliário para outras faixas de renda, inclusive do SBPE, como um fator essencial para o atendimento das camadas de baixa renda. Assim, ele explicitava a necessidade de criar subsídios diretos para a compra dos imóveis, semelhantes aos que seriam concedidos pelo FGTS a partir da resolução n. 460 (Instituto Cidadania, 2000, p. 87).

\section{Desconto para cotistas}

Conforme descrito anteriormente, o FGTS remunera os seus cotistas com valores historicamente abaixo da taxa de juros básica da economia, a taxa Selic. É essa remuneração relativamente baixa do seu cotista que permite, ao FGTS, fornecer empréstimos com juros abaixo dos cobrados pelo restante do mercado e, assim, cumprir seu papel de prover investimentos em habitação, saneamento e infraestrutura através de um subsídio implícito.

Até 2007 , os cotistas do fundo contratavam seus créditos habitacionais nas mesmas condições que os não cotistas. Isso mudou a partir de 2008, quando duas medidas do fundo passaram a privilegiá-los na tomada de crédito. Os titulares de contas há mais de três anos puderam contar com uma redução de $0,5 \%$ na sua taxa de juros ao contrair qualquer empréstimo junto ao fundo. A justificativa da resolução n. 537, que concedia esse desconto, explicitou como os trabalhadores formalizados se sentiam preteridos pelos benefícios do fundo, afirmando que a medida "trata de um resgate histórico do FGTS para com os trabalhadores titulares de conta vinculada" (Brasil, 2007).

Naquele mesmo momento, o fundo também implementou o Pró-Cotista, um programa voltado ao mesmo público-alvo (trabalhadores celetistas há mais de três anos). As entrevistas feitas para este trabaIho apontam que essas mudanças ocorreram por pressão dos trabalhadores celetistas, organizados nas centrais sindicais que possuíam assento no fundo.

Os benefícios previstos na resolução n. 537 foram os únicos descontos concedidos sem que o beneficiário necessariamente se enquadrasse no atendimento de "habitação popular" do fundo. Sendo assim, eles não seguiam limites de renda, mas somente os limites para o valor do imóvel estabelecidos pelo Conselho Monetário Nacional.

$\mathrm{O}$ atendimento do Pró-Cotista acabou concentrado em uma parcela da sociedade com poder aquisitivo maior do que a dos outros programas do fundo. 0 relatório do FGTS no ano de lançamento do fundo destacou que "embora não esteja vinculado ao orçamento da área de Habitação Popular, o Pró-Cotista inverteu, sobremaneira, a vocação histórica do FGTS de direcionar suas aplicações aos segmentos de menor renda" (CCFGTS, 2009). Naquele ano, $88 \%$ das aplicações do programa foram dirigidas à população com rendimento familiar mensal superior a 10 salários mínimos. O Pró-Cotista passou a atender, assim, a uma faixa de renda que poderia ser coberta pelo crédito com origem no SBPE. 


\section{Criação do FI-FGTS \\ e aquisição de Certificados \\ de Recebíveis Imobiliários}

Ao mesmo tempo que ampliava os seus subsídios, o crescimento constante do patrimônio líquido do FGTS, na primeira década dos anos 2000 , permitiu que o fundo buscasse novas destinações ao seu recurso, já que "para um Fundo com as características peculiares do FGTS, não há sentido algum em acumular um Patrimônio Líquido" (Eloy, 2013, p. 131).

Entre elas, esteve a criação do FI-FGTS, um fundo de investimento cujo único cotista é o próprio FGTS e que tinha por finalidade "investir em construção, reforma, ampliação ou implantação de empreendimentos em infraestrutura nos seguintes setores: rodovia, porto, hidrovia, ferrovia, energia, saneamento e aeroporto" (Brasil, 2007).

O FGTS já havia financiado obras de infraestrutura em meados dos anos 1970 (Silva, 1989), mas os investimentos do FI-FGTS são bastante distintos dos feitos anteriormente. Com o $\mathrm{Fl}$, o fundo não buscava fazer empréstimos diretos, mas a compra de ativos financeiros como debêntures e ações. Nessas circunstâncias, o Fl teria dois papéis: financiar a infraestrutura e melhor remunerar as contas dos trabalhadores, através da opção de compra de cotas de um fundo lastreado na carteira do Fl, com a implantação do Fundo de Investimento em Cotas do FI-FGTS (FIC FI-FGTS). Mas essa possibilidade de compra, prevista na concepção do fundo, jamais aconteceu.

O patrimônio líquido do FGTS acabou sendo a única origem de recursos do FI-FGTS. A lei que criou o fundo autorizava aplicação de $\mathrm{R} \$ 5$ bilhões do FGTS no fundo de investimento. Além disso, permitia a integralização máxima de $80 \%$ do patrimônio líquido do FGTS no fundo de investimento. Esses aportes no Fl-FGTS se concentraram entre 2008 e 2012, período de crescimento mais forte da economia e do patrimônio líquido do fundo.

Os investimentos do FI-FGTS buscavam uma rentabilidade que, posteriormente, deveria ser revertida ao próprio FGTS. Isso fez com que alguns gestores do fundo, em entrevista a este trabalho, afirmassem que ele não foi feito em detrimento da habitação para os setores de menor renda, mas que, na verdade, ajudou a viabilizá-los.

Além da compra de ativos financeiros através do FI-FGTS, o FGTS ainda expandiu seu investimento direto em títulos, em especial Certificados de Recebíveis Imobiliários. Assim, "de 2008 a 2012 os valores aplicados em operações de mercado foram sistematicamente maiores do que os alocados para subsídios habitacionais" (Royer, 2016, p. 45).

\section{Minha Casa Minha Vida}

A concessão de descontos atingiu seu maior valor a partir da criação do programa Minha Casa Minha Vida, em 2009 (Brasil, 2009). O programa foi gestado diante da crise econômica de 2008, e a iniciativa de fomentar a produção de moradias naquele momento parecia duplamente atraente: de um lado, estimulava-se a indústria e geravam-se empregos; do outro, enfrentava-se a absoluta precariedade que caracterizava a moradia da maior parte da população brasileira (Rolnik e Kazuo, 2008).

A legislação do Minha Casa Minha Vida não mudou substancialmente os sistemas já existentes de financiamento. Pelo 
contrário, usou o FGTS e outros fundos que já estavam constituídos, como o Fundo de Arrendamento Residencial e o Fundo de Desenvolvimento Social.

A União atuou com recursos não onerosos, especialmente através do Fundo de Arrendamento Residencial, o FAR, para atender às famílias da faixa 1 do programa, correspondente àquelas que recebem até $\mathrm{R} \$ 1.800$ por mês.

Mesmo com os aportes da União, o FGTS teve um papel central nesse financiamento e na concessão de subsídios, pois foi a principal fonte para as faixas 2 e 3 do programa, concedendo financiamentos e subsídios para famílias com renda de até $\mathrm{R} \$ 7.000$. Em valores nominais, os descontos concedidos somaram $\mathrm{R} \$ 57$ bilhões desde o início do programa até 2018.

O Minha Casa Minha Vida acabou com a necessidade de esgotar a capacidade de pagamento do preponente. Até então, a concessão de qualquer desconto estipulava a "utilização da capacidade de pagamento máxima do beneficiário, aferida pelos agentes financeiros" (Brasil, 2006). Com o Minha Casa Minha Vida, essa necessidade foi abolida (Brasil, 2008).

Fatores externos à modelagem do programa também são apontados como essenciais para o seu funcionamento naquela escala. Como aponta a ex-secretária nacional de habitação, Inês da Silva Magalhães:

Uma variável superimportante é a meIhoria da renda neste momento. Você pega a pirâmide de renda, nesse momento e você já começa a ter uma barriga no centro da pirâmide, uma melhora de renda. Então você conjuga incentivo à demanda, à oferta, à desoneração, a uma melhoria de renda e a um esquema de subsídio. Você cria uma equação capaz de criar uma virtuosidade nesse momento. (Magalhães, 2019)

Quadro 5 - Descontos do FGTS concedidos dentro do PMCMV/PNHU (em R\$ mil) 2009-2018

\begin{tabular}{|l|c|c|c|}
\hline Ano & Quantidade de moradias & Valor financiado & Total do desconto \\
\hline 2009 & 80.742 & 6.823 .675 & 2.193 .653 \\
2010 & 244.669 & 22.331 .382 & 6.203 .059 \\
2011 & 248.438 & 23.487 .370 & 6.484 .682 \\
2012 & 292.468 & 29.161 .449 & 8.048 .614 \\
2013 & 320.359 & 33.678 .865 & 9.310 .450 \\
2014 & 318.775 & 33.888 .803 & 8.796 .599 \\
2015 & 314.595 & 32.110 .246 & 7.781 .385 \\
2016 & 274.483 & 27.748 .631 & 6.490 .518 \\
2017 & 299.691 & 30.240 .686 & 8.142 .861 \\
2018 & 328.303 & 32.975 .614 & 8.898 .671 \\
\hline
\end{tabular}

Fonte: Brasil (2019). Valor corrigido com base no IPCA, considerando como base dezembro de cada ano e atualizando os valores para dezembro de 2018. 
Assim, o programa Minha Casa Minha Vida manteve as mesmas estruturas do SFH e produtos semelhantes àqueles que já eram financiados pelo FGTS anteriormente. Segundo Hereda (2019), não era possível fazer uma "coisa muito diferente do que o que os que vão produzir conhecem, se não demoraria um tempo muito grande para maturar".

A concessão de subsídios, durante toda a primeira fase do Minha Casa Minha Vida, foi regida pela resolução n. 460 . Ainda que ela tenha sido modificada pontualmente para a viabilização do programa, a resolução foi prorrogada até o lançamento da segunda fase do Minha Casa Minha Vida, quando foi substituída pela resolução n. 702 .

\section{Subsídios em período de austeridade}

O Brasil passou por relevantes mudanças econômicas a partir de 2013. Com a justificativa de conter a inflação, a taxa Selic foi elevada a patamares semelhantes aos encontrados em 2006. Essa inflexão da taxa de juros sinalizou uma mudança da política que vinha sendo adotada ao menos desde a crise de 2008, quando havia uma predominância de medidas anticíclicas de influência desenvolvimentista. A partir de 2013, as políticas de caráter desenvolvimentista deram lugar a políticas de austeridade de caráter ortodoxo (Singer, 2015).

Diante desse cenário, o crédito público baseado em fundos compulsórios ganhou ainda mais importância na economia, já que o financiamento fornecido pelos bancos privados se tornou mais escasso e caro. Em contraste com o orçamento de seguridade social do Governo Federal, que sofreu cortes nesse período, o orçamento do FGTS mostrou resiliência. Os gastos com habitação passaram de $R \$ 52.808 .305 .160$ (em valores corrigidos) em 2012 para $R \$ 70.968 .343 .878$ em 2016 um aumento real de $34 \%$.

Quadro 6 - Orçamento do FGTS por setor entre 2007 e 2016

\begin{tabular}{|c|c|r|r|r|r|}
\hline Ano & Habitação & \multicolumn{1}{c|}{$\begin{array}{c}\text { Desconto } \\
\text { financeiro }\end{array}$} & \multicolumn{1}{c|}{$\begin{array}{c}\text { Saneamento } \\
\text { básico }\end{array}$} & \multicolumn{1}{c|}{ Infraestrutura } & Total \\
\hline 2007 & $12.863 .657 .925,00$ & $3.489 .767 .466,00$ & $6.001 .672 .053,00$ & $1.368 .312,00$ & $22.356 .465 .756,00$ \\
2008 & $17.645 .993 .310,00$ & $2.786 .209 .470,00$ & $10.047 .240 .210,00$ & $1.688 .611 .800,00$ & $32.168 .054 .790,00$ \\
2009 & $32.215 .480 .000,00$ & $6.655 .718 .168,00$ & $7.409 .560 .400,00$ & $1.610 .774 .000,00$ & $47.891 .532 .568,00$ \\
2010 & $48.084 .250 .054,00$ & $8.272 .903 .375,00$ & $7.538 .642 .840,00$ & $18.027 .189 .400,00$ & $81.922 .985 .669,00$ \\
2011 & $55.353 .122 .000,00$ & $8.096 .866 .250,00$ & $7.066 .356 .000,00$ & $5.888 .630 .000,00$ & $76.404 .974 .250,00$ \\
2012 & $52.808 .305 .160,00$ & $9.616 .154 .242,00$ & $7.003 .754 .000,00$ & $7.003 .754 .000,00$ & $76.431 .967 .402,00$ \\
2013 & $48.332 .248 .800,00$ & $11.563 .360 .600,00$ & $6.756 .120 .800,00$ & $9.094 .778 .000,00$ & $75.746 .508 .200,00$ \\
2014 & $56.172 .852 .975,00$ & $10.957 .866 .010,00$ & $9.299 .042 .091,00$ & $13.646 .359 .967,00$ & $90.076 .121 .043,00$ \\
2015 & $67.860 .343 .958,00$ & $10.569 .451 .320,00$ & $6.018 .933 .190,00$ & $10.688 .209 .200,00$ & $95.136 .937 .668,00$ \\
2016 & $70.968 .343 .878,00$ & $9.561 .281 .570,00$ & $3.760 .054 .550,00$ & $10.205 .862 .350,00$ & $94.495 .542 .348,00$ \\
\hline
\end{tabular}

Fonte: elaboração própria a partir de relatórios de gestão do FGTS. Valor corrigido com base no IPCA, considerando como base dezembro de cada ano e atualizando os valores para dezembro de 2018. 
Quadro 7 - Orçamento final do FGTS entre 2012 e 2017 (em R\$ mil)

\begin{tabular}{|l|r|r|r|r|r|r|}
\hline Programa/Compra & \multicolumn{1}{c|}{$\mathbf{2 0 1 2}$} & \multicolumn{1}{c|}{$\mathbf{2 0 1 3}$} & \multicolumn{1}{c|}{$\mathbf{2 0 1 4}$} & \multicolumn{1}{c|}{$\mathbf{2 0 1 5}$} & \multicolumn{1}{c|}{$\mathbf{2 0 1 6}$} & $\mathbf{2 0 1 7}$ \\
\hline Apoio à produção & $28.471 .401,29$ & $30.701 .341,98$ & $23.420 .873,14$ & $27.077 .863,96$ & $31.777 .042,19$ & $32.638 .887,12$ \\
Carta de crédito & $53.485 .287,50$ & $62.331 .044,16$ & $56.538 .496,59$ & $57.267 .476,25$ & $58.553 .776,16$ & $57.727 .885,84$ \\
CRI & $3.567 .655,75$ & $3.372 .892,00$ & $2.215 .770,90$ & $687.653,10$ & $10.712 .363,00$ & 0 \\
Pró-Cotista & $71.353,12$ & $404.747,04$ & $1.076 .231,58$ & $7.648 .994,65$ & $9.212 .632,18$ & $8.065 .231,70$ \\
Pró-Moradia & $243.608,10$ & $1.349 .156,80$ & $151.938,58$ & 0 & 0 & 0 \\
Operações especiais & 0 & 0 & 0 & $1.432 .610,63$ & $2.999 .461,64$ & $375.127,06$ \\
\hline
\end{tabular}

Fonte: elaboração própria a partir dos relatórios de gestão do fundo, considerando somente os programas e compras voltados à habitação e ao setor imobiliário. Valor corrigido com base no IPCA, considerando como base dezembro de cada ano e atualizando os valores para dezembro de 2018.

Em todo esse período, o orçamento destinado aos programas de habitação ${ }^{1}$ superou $60 \%$ dos gastos do fundo, indo ao encontro de suas normas (Brasil, CCFGTS, 2012). Mas, ainda que o orçamento do FGTS para a habitação tenha se mostrado resiliste, ele passou por diversas modificações no período. 0 orçamento para os descontos do FGTS manteve-se constante nominalmente entre 2013 e 2016, no valor de $\mathrm{R} \$ \mathbf{8 , 9}$ bilhões - uma perda real de $33 \%$ no período, considerando a inflação desse mesmo período.

Além disso, as faixas de renda que podiam ser atendidas pelos descontos foram elevadas nesse período. Até então, os subsídios só poderiam ser concedidos para famílias com renda mensal limitada a $\mathrm{R} \$ 4.300$ e $\mathrm{R} \$ 5.400$ em Regiões Metropolitanas (ibid.). Com a mudança, os descontos do fundo passaram a atender às famílias com renda de até $\mathrm{R} \$ 7.000 \mathrm{em}$ qualquer cidade do País (CCFGTS, 2017).
O programa Pró-Moradia não fez nenhuma seleção entre 2015 e 2017, "em razão de não haver limite para concessão de crédito ao setor público, estabelecido pelo Conselho Monetário Nacional" (CCFGTS, 2018). Outra linha que teve orçamento destinado nesse período, mas que jamais o executou, foi o, Financiamento de Material de Construção (Fimac). Essa linha nunca foi efetivada porque impunha custos operacionais que ultrapassavam o valor de remuneração fixado pelo Conselho Curador (2,16\% ao ano) (CCFGTS, 2015), e o orçamento destinado a ela nos anos de 2013 a 2015 foi realocado para a área de habitação.

Ainda no mesmo período, foi criada a Faixa 1,5 do Minha Casa Minha Vida para atender às famílias com renda mensal de até $\mathrm{R} \$ 2.350$ com recursos do OGU e do FGTS. A ideia inicial do governo era atender a municípios específicos, nos quais parte da população ultrapassava os limites de renda familiar da faixa 1 do programa. 
Tabela 3 - Descontos concedidos pelo FGTS em 2017 (em R\$ milhares)

\begin{tabular}{|c|c|c|c|c|}
\hline Tipo de desconto & Desconto orçado & $\begin{array}{c}\text { Desconto } \\
\text { complemento }\end{array}$ & Desconto equilíbrio & Total desconto \\
\hline PMCMV faixas 2 e 3 & \multirow{3}{*}{$10.200 .000,00$} & $2.219 .310,00$ & $4.149 .433,00$ & $6.368 .743,00$ \\
\hline PMCMV faixa 1,5 & & $797.497,00$ & $648.260,00$ & $1.445 .757,00$ \\
\hline Demais aplicações & & $96.862,00$ & $620.973,00$ & $717.834,00$ \\
\hline
\end{tabular}

Fonte: Relatório de Gestão do FGTS de 2017 (CCFGTS, 2018). Valores correntes à época da publicação do relatório.

Isso não aconteceu porque, como explica Chaves (2019), as pressões dos municípios fizeram com que o projeto fosse aplicado a todas as cidades, sem um processo de seleção ou especificação de unidade (Chaves, 2019).

A faixa 1,5 correspondeu à menor parte dos descontos desembolsados no período. Em 2017, por exemplo, os financiamentos ligados à faixa 1,5 receberam menos descontos do que os ligados às faixas 2 e 3 do programa. Percebe-se, também, que os desembolsos relacionados ao desconto equilíbrio foram superiores àqueles direcionados ao desconto complemento nas faixas 2 e 3 do Minha Casa Minha Vida.

As demais operações que recebiam subsídios do fundo se referiam, especialmente, ao Programa Carta de Crédito Individual, que englobava operações que não se encaixavam no MCMV. Em 2017, 90\% dos subsídios aplicados em "demais aplicações" estavam dentro do programa, um valor superior àquele aplicado na faixa 1,5 do Minha Casa Minha Vida.

Nesse período, o FGTS também fez pelo menos dois movimentos direcionados às parcelas de maior renda da sociedade. Um deles foi a expansão do orçamento e do desembolso com o Pró-Cotista, que cresceu nesse período. Buscando compensar a queda de recursos no SBPE, o Conselho Curador do FGTS expandiu o orçamento do Pró-Cotista, que foi contratado quase em sua totalidade naquele ano. Com o aumento nos limites dos imóveis que poderiam ser atendidos dentro do SFH, o Pró-Cotista financiou unidades que poderiam alcançar até $\mathrm{R} \$ 1,5$ milhão, enquanto a área de habitação popular estava limitada ao valor máximo de R\$240 mil (CCFGTS, 2018).

O fundo também passou a alocar recursos nas chamadas "operações especiais", concedidas diretamente a pessoas jurídicas cuja demanda não se encaixava necessariamente na área de habitação popular do fundo. Assim como o Pró-Cotista, essas operações concediam empréstimos sem um limite de renda. Em contrapartida, o conselho do fundo estabeleceu o limite de 300 mil reais por unidade habitacional, abaixo dos limites estabelecidos pelo Conselho Monetário Nacional $(\mathrm{CMN})$, sob o argumento de que assim esses 
Tabela 4 - Atendimento do programa Pró-Cotista em 2017

\begin{tabular}{l|c|c}
\hline \multicolumn{1}{c|}{ Faixa de renda - R\$ } & $\begin{array}{c}\text { Quantidade } \\
\text { de operações }\end{array}$ & $\begin{array}{c}\text { Valor financiado } \\
\text { (em R\$ mil) }\end{array}$ \\
\hline até $\mathrm{R} \$ 1.800,00$ & 6 & 290 \\
de $\mathrm{R} \$ 1.800,01$ a $\mathrm{R} \$ 3.600,00$ & 976 & 75.906 \\
de $\mathrm{R} \$ 3.600,01 \mathrm{~A} \mathrm{R} \$ 6.500,00$ & 8.386 & 1.058 .115 \\
acima de $\mathrm{R} \$ 6.500,00$ & 28.242 & 5.578 .535 \\
\hline Total & 37.610 & 6.712 .846 \\
\hline
\end{tabular}

Fonte: Relatório de Gestão do FGTS de 2017 (CCFGTS, 2018). Valores correntes à época da publicação o relatório.

empréstimos estariam mais aderentes aos objetivos sociais do fundo (CCFGTS, 2015).

Posteriormente, em 2017, o FGTS elevou a faixa de renda que podia ser atendida dentro dos seus programas. 0 limite de renda familiar foi ampliado de $\mathrm{R} \$ 7.000$, para $\mathrm{R} \$ 9.000$ naquele ano (CCFGTS, 2017).

Nesse período guiado por políticas de austeridade, o fundo também continuou a comprar títulos ligados ao SFI. A partir de 2012, a compra de CRIs (Certificado de Recebíveis Imobiliários) pelo FGTS esteve em queda e chegou ao seu menor valor em 2015. Porém, a compra desses títulos dá um salto em 2016, quando alcança seu maior valor, e seu orçamento chega a R\$9 bilhões em valores nominais - o mesmo valor que foi alocado em descontos pelo fundo naquele ano.

Além da compra de CRls, o fundo adquiriu pela primeira vez outro título criado pelo SFI. Em 2016, o Conselho Curador permitiu a aquisição de LCls (Letras de Crédito Imobiliário) pelo fundo. Ao justificar a proposta, o conselho considerou "a necessidade de fomentar o crédito habitacional no país, haja vista os reflexos positivos e o seu efeito multiplicador sobre a atividade econômica em geral". Em seguida, justifica:

que o delicado cenário econômico refletiu negativamente na captação dos depósitos de poupança, que vem sofrendo perdas que alcançaram o patamar de R\$ 50 bilhões somente no último ano e que a falta desses recursos tem encarecido o custo das operações e distanciado as famílias brasileiras do acesso ao crédito para aquisição da moradia própria. (CCFGTS, 2016)

Assim, a exemplo do Pró-Moradia, a compra de LCls também é justificada pela queda de recursos disponíveis para financiamentos com lastro do SBPE. 


\section{A atuação do FGTS \\ na faixa 1 do Programa Minha Casa Minha Vida}

O FGTS também atuou junto às faixas de menor renda em 2015 e 2016, ao complementar o FAR na concessão de subsídios para a faixa 1 do Minha Casa Minha Vida. $O$ conselho curador autorizou o uso de FGTS para o "desconto nos financiamentos a pessoas físicas, exclusivamente para fins de pagamento de parte da aquisição de imóveis novos, produzidos no âmbito do Programa Minha Casa Minha Vida" (CCFGTS, 2017).

A autorização vigorou até 31 de dezembro de 2016. Em termos formais, o FAR alienava as suas unidades habitacionais, produzidas com recursos do OGU, e o FGTS financiava a aquisição dessas unidades. O aporte no FAR é justificado por dois motivos: as limitações do tesouro, que o impedem de cumprir obrigações já assumidas, e "o impacto negativo no nível de atividade econômica que o eventual fechamento" das empresas de construção geraria no mercado de trabalho (CCFGTS, 2016, p. 59). Conforme disposto, "o desembolso de valores relativos a descontos, concedidos a fundo perdido pelo FGTS, a partir de expectativa trimestral de vendas, pretendeu acelerar o processo de capitalização do FAR, diante do agravamento do contexto fiscal brasileiro". Os descontos concedidos dentro desse acordo prosseguiram no ano seguinte, conforme Quadro 8.

\section{Conclusão}

A revisão da trajetória dos subsídios concedidos pelo FGTS nesses vinte anos deixa claro o seu papel central no atendimento habitacional para a população de baixa renda. Isso é perceptível a partir das normas que regulam o fundo e dos dados sobre a sua concessão.

De maneira geral, o fundo ampliou os gastos cobertos por descontos desde que eles foram criados na década de 1990. Nos anos 2000, eles passaram a cobrir novos encargos, especialmente com a resolução n. 460 do CCFGTS. Com o programa Minha Casa Minha Vida, os financiamentos com lastro no FGTS, tiveram o seu maior crescimento absoluto.

Quadro 8 - Participação do FGTS no MCMV faixa 1

\begin{tabular}{|c|c|c|}
\hline Ano & Orçamento-R\$ & Valor Concedido- $\mathbf{R} \$$ \\
\hline 2015 & $3.795 .000,00$ & $3.412 .766,45$ \\
2016 & $5.184 .000,00$ & $5.167 .932,84$ \\
\hline
\end{tabular}

Fonte: elaboração própria a partir de dados do balanço do FGTS de 2017. Valor corrigido com base no IPCA, considerando como base dezembro de cada ano e atualizando os valores para dezembro de 2018. 
Essa trajetória, porém, não é linear ou coerente. Nesse período, o fundo também serviu como uma fonte de crédito barata para mercados de renda mais alta e outros setores da economia. O FGTS passou a ter uma linha de crédito utilizada especialmente pela população de mais alta renda, o Pró-Cotista, e uma série de regulações que lhe permitia investir em títulos financeiros, como debêntures, CRIs e LCls.

A trajetória díspar do FGTS ainda é vista claramente no período mais recente da economia brasileira, guiado por políticas econômicas voltadas à austeridade. Por um lado, o FGTS atendeu às parcelas de renda mais alta da população com o uso do Pró-Cotista, adquiriu CRIs, recebeu permissão para adquirir $\mathrm{LCls}$ e um dos seus principais programas para baixa renda, o Pró-Moradia, foi interrompido por fatores externos ao fundo. Por outro, o FGTS continuou a atender as parcelas de menor renda da população. Os descontos do FGTS nesse período se mantiveram nominalmente constantes, enquanto o Orçamento Geral da União sofreu cortes mais severos nos seus recursos destinados ao Minha Casa Minha Vida faixa 1. O FGTS cumpriria o papel até então destinado normalmente ao OGU de duas formas: com a criação da faixa 1,5 do Minha Casa Minha Vida e com investimentos diretos no atendimento da faixa 1 do fundo.

As regulações e o orçamento dos descontos demonstram essa dinâmica complexa do fundo. Os subsídios explícitos concedidos pelo FGTS têm a potencialidade de aumentar o alcance do atendimento do financiamento habitacional feito pelo fundo e, assim, são essenciais para que ele cumpra a sua função social. Mas a concessão de descontos, por si só, não redunda em um atendimento das parcelas de menor renda da população. Essa concepção errônea perpassa, por exemplo, os documentos do próprio fundo (CCFGTS, 2018).

Sendo assim, são necessários estudos mais detalhados para compreender efetivamente os efeitos dos descontos concedidos pelo fundo. A diferença dos impactos entre o desconto equilíbrio, voltado à cobertura do diferencial da taxa de juros e da taxa de administração, e do desconto complemento, voltado ao pagamento de parte da aquisição ou da construção do imóvel financiado, ainda carece de melhor compreensão. Também é importante entender melhor o impacto que operações voltadas à maior rentabilidade do fundo têm na concessão de créditos a fundo perdido.

A disputa pelos recursos do FGTS é feita dentro de regras pactuadas, especialmente no âmbito do seu Conselho Curador, por sua vez subordinado às decisões do poder Legislativo. Assim, também é necessário entender, por um lado, de que maneira diferentes agentes atuam sobre o fundo e suas estratégias e, por outro, como eles também buscam moldar essas regras.

\section{[I] https://orcid.org/0000-0001-7444-5780}

Universidade Federal do ABC, Centro de Engenharia, Modelagem e Ciências Sociais Aplicadas, Programa de Pós-Graduação em Planejamento e Gestão do Território. Santo André, SP/Brasil. pierobl@gmail.com 


\section{Nota}

(1) Isso também acontece quando é levada em consideração a metodologia do fundo para arbitrar o que é "habitação", que no ano de 2016 incluía os gastos com CRIs e LCls. Os "recursos globais do Orçamento Operacional" também têm variações ao longo dos anos nos demonstrativos do FGTS.

\section{Referências}

ARRETCHE, M. T. (1996). "Desarticulação do BNH e autonomização da política habitacional". In: AFFONSO, R. de B. A.; e SILVA, P. L. B. (orgs.). Descentralização e políticas sociais. São Paulo, Fundap.

(2002). Federalismo e relações Intergovernamentais no Brasil: a reforma de programas sociais. Dados. Rio de Janeiro, v. 45, n. 3, pp. 431-458.

AZEVEDO, S. DE; ANDRADE, L. A. G. DE (1982). Habitação e poder - Da fundação da casa popular ao Banco Nacional da Habitação. Rio de Janeiro, Zahar.

BONDUKI, N. (1998). Origens da habitação social no Brasil: arquitetura moderna, lei do inquilinato e difusão da casa própria. São Paulo, Estação Liberdade.

(2008). Política habitacional e inclusão social no Brasil: revisão histórica e novas perspectivas no governo Lula. Revista eletrônica de Arquitetura e Urbanismo, v. 1, n. 1, pp. 70-104.

BRASIL. CCFGTS (1995). Resolução n. 178, de 28 de abril de 1995. Aprova o Programa de Atendimento Habitacional através do Poder Público (Pró-Moradia). Diário Oficial da União, seção 1, Brasília, pp. 61-64, 5 maio.

CCFGTS (1998). Resolução n. 290, de 8 de março de 1988. Altera o Programa de Atendimento Habitacional através do Poder Público - Pró-Moradia. Diário Oficial da União, seção 1, Brasília, pp. 66-67, 8 jul.

CCFGTS (2001). Resolução n. 376. Prorroga a vigência da Resolução n. 289, de 30 de junho de 1998, e dá outras providências. Diário Oficial da União, seção 1. Brasília, 29 dez.

CCFGTS (2003a). Resolução n. 431, de 30 de outubro de 2003. Dispõe sobre a prorrogação da vigência da Resolução n. 289, de 30 de junho de 1998, e a alteração do calendário relativo ao processo orçamentário, e dá outras providências. Diário Oficial da União, seção 1. Brasília, p. 74, 5 nov.

CCFGTS (2003b). Resolução n. 434, de 16 de dezembro de 2003. Autoriza o remanejamento de valores entre os itens do orçamento de aplicações de 2003, sem alterar o valor global, e dá outras providências. Diário Oficial da União, seção 1. Brasília, p. 102, 23 dez.

CCFGTS (2006). Resolução n. 518, de 7 de novembro. Altera e consolida a Resolução n. 460, de 14 de dezembro de 2004, que dispõe sobre as diretrizes para a aplicação dos recursos e a elaboração das propostas orçamentárias do FGTS, no período de 2005 a 2008, e dá outras providências. Diário Oficial da União: seção 1, Brasília, pp. 66-67, 20 nov. 
BRASIL. CCFGTS (2008). Resolução n. 564, de 11 de junho. Dá nova redação aos subitens $1.5,9.1$ e 9.2 do Anexo II da Resolução n. 460, de 14 de dezembro de 2004, que dispõe sobre as diretrizes para a aplicação dos recursos e a elaboração das propostas orçamentárias do FGTS, no período de 2005 a 2008. Diário Oficial da União: seção 1, Brasília, p. 90, 13 jun.

(2012). Resolução n. 702, de 4 de outubro de 2012. Estabelece diretrizes para elaboração das propostas orçamentárias e aplicação dos recursos do Fundo de Garantia do Tempo de Serviço (FGTS), e dá outras providências. Diário Oficial da União, seção 1. Brasília, pp. 131-134, 5 nov.

BRASIL (1964). Lei n. 4.380, de 21 de agosto. Disponível em: <http://www.planalto.gov.br/ccivil_03/ leis//4380.htm>. Acesso em: 16 jun 2019.

(1986). Decreto-lei n. 2291 de 21 de novembro. Disponível em: <http://www.planalto.gov.br/ ccivil_03/decreto-lei/Del2291.htm>. Acesso em: 16 jun 2019.

(1988). Constituição Federal de 1988. Disponível em: < http://www.planalto.gov.br/ccivil_03/ constituicao/constituicao.htm>. Acesso em: 16 jun 2019.

(1998a). Congresso Nacional. Diário do Congresso Nacional, Brasília, ano 53, 29 jun. Disponível em: <https://legis.senado.leg.br/diarios/BuscaDiario?codDiario=14293\#diario>. Acesso em: Acesso em: 16 jun 2019.

(1998b). Medida Provisória n. 1.671 de 24 de junho. Disponível em: <http://www.planalto.gov. br/ccivil_03/mpv/Antigas/1671.htm>. Acesso em: 16 jun 2019.

(1999). Medida Provisória n. 1.823 de 29 de abril. Disponível em: <http://www.planalto.gov.br/ ccivil_03/mpv/antigas/1823.htm>. Acesso em: 16 jun 2019.

(2004). Lei n. 10.931 de 2 de agosto. Disponível em: < http://www.planalto.gov.br/CCIVIL_03/_ Ato2004-2006/2004/Lei/L10.931.htm>. Acesso em: 16 jun 2019.

(2005). Lei n. 11.124, de 16 de junho. Disponível em: < http://www.planalto.gov.br/ccivil_03/_ Ato2004-2006/2005/Lei/L11124.htm>. Acesso em: 16 jun 2019.

(2007). Lei n. 11.491, de 20 de junho. Disponível em: < http://www.planalto.gov.br/ccivil_03/_ Ato2007-2010/2007/Lei/L11491.htm>. Acesso em: 16 jun 2019.

(2009). Lei n. 11.977, de 7 de julho. Disponível em: < http://www.planalto.gov.br/ccivil_03/_ ato2007-2010/2009/lei/l11977.htm>. Acesso em: 16 jun 2019.

CCFGTS - Conselho Curador do FGTS (1998). Resolução 289, de 30 de junho de 1998. Estabelece diretrizes para a aplicação dos recursos e a elaboração das propostas orçamentárias do FGTS, no período de 1998 a 2001. Diário Oficial da União, seção 1, Brasília, pp. 65-66, 8 jul 1998.

(2009). Relatório de Gestão Fundo de Garantia do Tempo de Serviço - 2008. Brasília.

(2015). Relatório de Gestão Fundo de Garantia do Tempo de Serviço - 2014. Brasília.

(2016). Relatório de Gestão Fundo de Garantia do Tempo de Serviço - 2015. Brasília.

(2017). Relatório de Gestão Fundo de Garantia do Tempo de Serviço - 2016. Brasília.

(2018). Relatório de Gestão Fundo de Garantia do Tempo de Serviço - 2017. Brasília. 
CARDOSO, A. L.; ARAGÃO, T. A. (2013). “Do fim do BNH ao Programa Minha Casa Minha Vida: 25 anos da política habitacional no Brasil". In: CARDOSO, A. L. (org.). O programa Minha Casa Minha Vida e seus efeitos territoriais. Rio de Janeiro, Letra Capital.

CARDOSO, A. L.; JAENISCH, S. T. ; YASSU, A. M. S. ; PINA, A. M. ; XIMENES, L. (2018). O FGTS em disputa: Pressões sobre o uso de fundos públicos em um contexto de crise institucional. In: SEMINÁRIO INTERNACIONAL FINANCEIRIZAÇÃO E ESTUDO URBANOS: OLHARES CRUZADOS EUROPA E AMÉRICA LATINA. Anais... São Carlos, SP.

CBIC (2019). Banco de Dados - CBIC. Disponível em: <http://www.cbicdados.com.br/menu/ financiamento-habitacional/sbpe>. Acesso em: 8 jun 2019.

CHAVES, M. Q. B. (2019). Entrevista concedida a Piero Locatelli, abril.

CINTRA, M. A. M. (2009). “Crédito público e desenvolvimento econômico: a experiência brasileira”. In: FERREIRA, F. M. R.; MEIRELLES, B. B. Ensaios sobre economia financeira. Rio de Janeiro, BNDES.

ELOY, C. M. (2013). O papel do Sistema Financeiro da Habitação diante do desafio de universalizar o acesso à moradia digna no Brasil. Tese de doutorado. São Paulo, Universidade de São Paulo.

ELOY, C. M.; COSTA, F.; ROSSETTO, R. (2013). “Direito à moradia no Brasil: a política de subsídios habitacionais". In: FAGNANI, E.; FONSECA, A. (orgs.). Políticas sociais, universalização da cidadania e desenvolvimento: educação, seguridade social, infraestrutura urbana, pobreza e transição demográfica. São Paulo, Fundação Perseu Abramo.

HEREDA, J. F. (2018). Entrevista concedida a Piero Locatelli, dez.

HOEK-SMIT, M. C.; DIAMOND, D. (2003). The design and implementation of subsidies for housing finance. In: WORLD BANK SEMINAR ON HOUSING FINANCE, March. Anais... Washington.

INSTITUTO CIDADANIA (2000). Projeto Moradia. Disponível em: <https://erminiamaricato.files. wordpress.com/2015/07/projeto-moradia.pdf>. Acesso em: 16 jun 2019.

LORENZETTI, M. S. B. (2001). A questão habitacional no Brasil. Brasília, Câmara dos Deputados [Estudo].

MAGALHÃES, I. DA S. (2019). Entrevista concedida a Piero Locatelli, março.

MAGNABOSCO, A. L.; FREITAS, F. G. DE (2015). "The Brazilian housing policy". In: FREITAS, F. G.; WHITEHEAD, C.; SANTA ROSA, J. Finance and subsidy policies in Brazil and European Union: a comparative analysis. Brasília, Ministério das Cidades (Cities Alliance).

MARICATO, E.; ROYER, L. A. (2017). "Política urbana e de habitação”. In: MARINGONI, G.; MEDEIROS, J. (orgs.). Cinco mil dias: o Brasil na era do lulismo. São Paulo, Boitempo.

OLIVEIRA, F. DE (1988). O surgimento do antivalor: capital, força de trabalho e fundo público. Novos estudos Cebrap. São Paulo, v. 22, pp. 8-22.

POCHMANN, M. (2004). Proteção social na periferia do capitalismo: considerações sobre o Brasil. São Paulo em Perspectiva. São Paulo, v. 18, n. 2, pp. 3-16.

ROLNIK, R.; KAZUO, A. (2008). As armadilhas do pacote habitacional. Disponível em: <https:// diplomatique.org.br/as-armadilhas-do-pacote-habitacional/>. Acesso em: 16 jun 2019. 
ROYER, L. (2009). Financeirização da política habitacional: limites e perspectivas. Tese de doutorado. São Paulo, Universidade de São Paulo.

(2016). O FGTS e o mercado de títulos de base imobiliária: relações e tendências. Cadernos Metrópole. São Paulo v. 18, n. 35, pp. 33-52.

SILVA, M. O. DA (1989). Política habitacional brasileira: verso e reverso. São Paulo, Cortez.

SINGER, A. (2015). Cutucando onças com varas curtas. Novos Estudos Cebrap. São Paulo, v. 102, pp. 39-67. TRINDADE, M. (1971). Habitação e desenvolvimento. São Paulo, Vozes.

Texto recebido em 8/dez/2019

Texto aprovado em 20/abr/2020 